This item was submitted to Loughborough's Research Repository by the author.

Items in Figshare are protected by copyright, with all rights reserved, unless otherwise indicated.

\title{
Carbohydrate needs of the young athlete
}

PLEASE CITE THE PUBLISHED VERSION

https://www.crcpress.com/Sports-Nutrition-Needs-for-Child-and-Adolescent-Athletes/Kerksick-

Fox/p/book/9781466579750

\section{PUBLISHER}

(C) CRC Press.

\section{VERSION}

AM (Accepted Manuscript)

\section{PUBLISHER STATEMENT}

This work is made available according to the conditions of the Creative Commons Attribution-NonCommercialNoDerivatives 4.0 International (CC BY-NC-ND 4.0) licence. Full details of this licence are available at: https://creativecommons.org/licenses/by-nc-nd/4.0/

\section{LICENCE}

CC BY-NC-ND 4.0

\section{REPOSITORY RECORD}

Zakrzewski, Julia K., and Keith Tolfrey. 2019. "Carbohydrate Needs of the Young Athlete". figshare. https://hdl.handle.net/2134/24312. 


\section{Carbohydrate Needs of the Young Athlete}

\section{Julia K Zakrzewski and Keith Tolfrey}

\section{Introduction}

Good nutritional practice is essential for both health and exercise performance in athletes. Although young people today are generally less active and heavier than recommended, numbers of young athletes involved in competitive sport and intense regular training with high energy expenditures have increased in recent years (Malina, 2010). Ensuring adequate energy is available to meet the demands of high energy expenditures is important in the young athlete to ensure proper growth, development, and maturation (Malina, 2010). Physiological and metabolic changes that accompany the transition from childhood to adolescence and to adulthood, combined with the additional energy expenditure arising from exercise, mean that the dietary needs of young athletes require special consideration.

Carbohydrate (CHO) intake provides the majority of energy in the diet and is also essential to fuel high intensity exercise. Dietary CHO intake in young athletes may be evaluated in terms of both the total daily intake and the timing of consumption in relation to exercise; these factors can determine whether adequate $\mathrm{CHO}$ substrate is available for muscles and the central nervous system (CNS) or whether CHO fuel sources might limit exercise performance. Although the CHO needs of adults have been well-documented, little research attention has been given to child and adolescent populations; this is surprising given the plethora of physical, physiological and metabolic child-adult differences that are seen in the pediatric sport and exercise science literature. Therefore, there is no doubt that specific evidence focusing on young athletes is required to inform $\mathrm{CHO}$ recommendations tailored to this age group. This chapter provides an overview of the available evidence that can be used to inform 
recommendations for $\mathrm{CHO}$ intake and timing in young athletes. Where no direct evidence in young athletes is available, we have relied on the relevant adult-based literature whilst emphasising that the direct translation and application of these findings to children and adolescents must be viewed cautiously.

\section{Recommended values for CHO intake for young athletes}

The Dietary Guidelines for Americans (U.S. Department of Health and Human Services \& U.S. Department of Agriculture, 2010) provide estimated daily energy needs by age, sex, and physical activity level (Table 1). The latest edition of these guidelines was released in 2010 and is available online (www.health.gov/dietaryguidelines/2010.asp). Rather than using kilojoules (kJ; the SI unit), the recommendations for energy intake are provided in kilocalories (kcal), which typically provide more meaningful values for the general public to interpret. The Institute of Medicine (2002) has established ranges for the percentage of energy (kcal) in the diet that should come from $\mathrm{CHO}$, protein, and fat; these Acceptable Macronutrient Distribution Ranges (AMDR) take into account both chronic disease risk reduction and intake of essential nutrients. However, unlike daily total energy intake, recommendations for $\mathrm{CHO}$ intake have not been stratified by physical activity level, age or sex; the AMDR is 45 to $65 \%$ of total energy intake. Combining these details with the recommendations in Table 1, older and more active children should consume more CHO (g) due to the higher total energy intake that is recommended. Accordingly, perhaps it would be preferable for young athletes to aim to consume the amount of $\mathrm{CHO}$ (g) equal to 45 to $65 \%$ of daily energy within the 'active' energy intake category of Table 1. For example, a 12 year old female athlete should consume 1800 to 2200 kcal per day, with 203 to 248 g (45\% of total kcal) to 293 to $358 \mathrm{~g}$ (65\% of total kcal) from CHO. However, the Dietary Reference Intake 
(DRI) remains at $100 \mathrm{~g} \cdot \mathrm{d}^{-1}$ and Recommended Dietary Allowance (RDA) at $130 \mathrm{~g} \cdot \mathrm{d}^{-1}$ for all age and sex categories (children $\geq 1$ year), which are not specific to physical activity level.

For young athletes, the RDAs appear to require further consideration due to the additional energy expenditures in this population. The American College of Sports Medicine (ACSM, 2009) recommendations that adult athletes should consume 6 to $10 \mathrm{~g} \cdot \mathrm{CHO} \cdot \mathrm{kg}^{-1} \cdot \mathrm{body}$ mass ${ }^{-1}$ each day, depending on the athlete's total daily energy expenditure, type of sport, sex, and environmental conditions, but excludes children and adolescents explicitly from these recommendations. Based on the combination of a higher reliance on fat as a fuel, lower glycogen stores and limited glycolytic capacity in younger athletes, they may require less dietary CHO (\% total energy intake) than adults (see section 4). The American Dietetic Association have provided some general guidance for adolescent athletes, recommending the consumption of a training diet that meets nutrition needs for physical activity and health with 55 to $60 \%$ of total energy from CHO (Steen, 1996). They also emphasise the importance of a diet including variety, balance, moderation in food choices and targeting athletes with an increased risk for developing eating disorders. However, no specific guidelines for prepubertal children were provided due to the lack of child-specific evidence.

\section{Current levels of $\mathrm{CHO}$ intake in young athletes}

Nutritional surveys reporting $\mathrm{CHO}$ intakes of young athletes are important in identifying groups or individuals who may be at risk of inadequate dietary $\mathrm{CHO}$ consumption. The increased independence and peer pressure that often accompanies adolescence can influence food selections, which may lead to certain nutrient deficiencies and an increased risk of negative health consequences; for example stunted growth, loss of lean body mass, reduced 
bone mineral content or density, fatigue, delayed injury recovery, menstrual dysfunction and diminished performance (Malina, 2010; Tamminen and Crocker, 2012).

A number of small-scale studies have assessed daily absolute CHO intake in young athletes examples are displayed in Table 2. Intakes are likely influenced by a number of factors including age, sex, body composition, specific event and/or sport. Even when considering only a single sport, assessments of CHO intakes have shown daily values ranging from 293 to 469 g, corresponding to 41 to 55\% daily energy intake, in adolescent association football players (Bar-Or \& Unnithan, 1994; Boisseau et al., 2002; Giovannini et al., 2000; IglesiasGutiérrez et al. 2005; Rico-Sanz et al. 1998). For female adolescents, CHO represented 54\% of total energy intake in athletes of various sports (Cupisti et al. 2002), but only 46\% of total energy in volleyball players (Papadopoulou et al. 2002) were found. However, longitudinal nutrient intake assessments are needed to estimate any changes in $\mathrm{CHO}$ intake in relation to growth. In a three year follow-up study of 19 young French association football players, daily CHO intake increased from $320 \mathrm{~g}$ to $360 \mathrm{~g}$ from 13 to 14 years and then to $396 \mathrm{~g}$ at 15 years of age, but did not increase when expressed per kg body mass (Leblanc et al. 2002). A three year longitudinal study in female runners reported an increased $\mathrm{CHO}$ intake relative to total energy intake, but decreased total absolute energy and CHO intakes (Wiita and Stombaugh, 1996). Further longitudinal nutritional surveys that consider age, sex, puberty, body composition and sport or specific event would provide valuable information on current $\mathrm{CHO}$ intakes in young athletes and changes with growth.

It is difficult to ascertain whether reported CHO intakes are adequate for health and performance due to the lack of specific $\mathrm{CHO}$ intake recommendations in young athletes that account for individual considerations, such as age, sex body composition and training load 
(see section 2). However, it may be possible to identify certain groups susceptible to 'low' $\mathrm{CHO}$ intakes, where sex appears to be an important factor. Intake of $\mathrm{CHO}$ is generally higher in boys (6 and $9 \mathrm{~g} \cdot \mathrm{kg}^{-1}$ ) (Chen et al., 1989; Leblanc et al., 2002; Montfort-Steiger et al., 2005) compared with girls (3 to $5.5 \mathrm{~g} \cdot \mathrm{kg}^{-1}$ ) (Cupisti et al., 2002; Papadopoulou et al., 2002; Wiita and Stombaugh, 1996). The prevalence of eating disorders is also higher in adolescent female than male athletes, as well as being higher in elite athletes compared with non-athletes (Martinsen and Sundgot-Borgen, 2013). Reports of disordered eating and low energy intakes in young athletes competing in specific sports is also likely to place individuals at risk of inadequate $\mathrm{CHO}$ intake. Events where it is seen as an advantage to remain lean, have an aesthetically appealing appearance, and weight-class sports all carry an increased risk of low energy and $\mathrm{CHO}$ intakes. Thus, athletes including distance runners, figure skaters, divers, synchronized swimmers, rhythmic dancers, gymnasts, and boxers may require special attention (Manore, 2002). Restricted eating with the belief that it can delay puberty is a concern among young girls participating in aesthetic sports (Malina, 2010), but is fairly simple to identify using specific questionnaires. For example, the children's Dutch Eating Behaviour Questionnaire (DEBQ) for the measurement of restrained, emotional and external eating (van Strien and Oosterveld, 2008) may be a useful tool for coaches and parents to screen young athletes for restrictive eating and inadequate CHO intakes.

\section{Child-adult metabolic differences}

An insight into exercise substrate metabolism in children and adolescents underpins our understanding of young athletes' CHO needs. Differences in substrate metabolism between children and adults have been known for some time now. Over 70 years ago it was demonstrated that children have lower respiratory exchange ratio (RER) values during exercise compared with adults, indicating a higher reliance on fat and lower reliance on $\mathrm{CHO}$ 
oxidation (Robinson, 1938). Subsequently, lower RER values have been observed in boys and girls compared with adults during submaximal exercise performed at similar absolute (Montoye, 1982) and relative (Foricher et al., 2003; Martinez and Haymes, 1992) exercise intensities. Prepubertal boys and girls also have low $\mathrm{CHO}$ oxidation rates compared with matched sex adolescents during exercise at the same relative intensity (Timmons et al., 2007a; 2007b), suggesting puberty may modulate these changes in fat oxidation. Data are not entirely consistent in females, however, with some studies indicating that girls and women exhibit similar contributions of fat oxidation to energy expenditure (Rowland and Rimany 1995). Discrepancies in the results of studies investigating females (Martinez and Haymes, 1992; Rowland and Rimany 1995) may be due to inadequate control for the menstrual cycle (Oosthuyse and Bosch, 2010).

Possible mechanisms that can explain the lower reliance on $\mathrm{CHO}$ and higher reliance on fat as fuels at rest and during exercise in children are unclear. The commonly held belief that children have an underdeveloped glycolytic system was based initially on a series muscle biopsy studies with a small sample of boys by Eriksson and colleagues more than 40 years ago, reviewed by Eriksson (1980). In these studies, the glycogen content of muscle in 11 to 16 year old boys was 50 to $60 \%$ lower than reported in untrained adults (Eriksson et al. 1973) and increased with maturation (Eriksson and Saltin 1974). The activity of the rate limiting enzyme for glycolysis in 11 year old boys, phosphofructokinase (PFK), was only approximately $30 \%$ of that reported in published studies of untrained men (Eriksson et al. 1973). Although other researchers have not measured PFK, quantification of other glycolytic enzyme activities from muscle biopsies have proffered equivocal results. In a mixed sex comparison of 8 six year old children with 12 thirteen year old mid-adolescents and 13 seventeen year old young adults, lactate dehydrogenase (LDH) activity was highest in the 
adolescents (143\%>children; 55\%>young adults; Berg et al. 1986). Although aldolase and pyruvate kinase were also greatest in the adolescent group, the enzyme activities were only significantly higher than the children not the young adults (Berg et al. 1986).

In contrast, several oxidative enzymes including succinic dehydrogenase (SDH), fumarase and isocitrate dehydrogenase (ICDH) measured in young boys and adolescent girls were considerably higher when compared directly and indirectly with activities at physiologic temperatures in men and women (Eriksson et al. 1973; Haralambie, 1979; 1982). The young children in Berg's study (1986) had 40\% higher fumarase activity than the young adults; furthermore, when the data for the three age groups were pooled $(n=33$; age range 3 to 19 years) fumarase was inversely related to chronological age $\left(r^{2}=0.23\right)$. Comparing the ratio of PFK to ICDH (glycolytic:oxidative) activity in a mixed sex group of adults and 13 to 15 year old adolescent girls, Haralambie (1982) found it doubled in adults (1.63 vs. 0.84). This strongly suggests that oxidation of tricarboxylic acid cycle intermediates is more prominent during adolescence than glycolysis. Some of the enzymes included in these studies were described as equilibrium or non-rate limiting, which may diminish their influence on the flux through physiologic pathways; more importantly, the comparisons between young people and adults were indirect in the Scandinavian studies, and all of the studies were with small sample sizes because of the ethical and logistical difficulties in obtaining tissue samples from this population. Nevertheless, there is evidence supporting the lower lactate dehydrogenase (LDH) activity (Kaczor et al., 2005) and blood lactate concentration during exercise (Mácek et al., 1976; Mahon et al., 1997) in young people compared with adults. This is important as lactate, an intermediate of $\mathrm{CHO}$ oxidation, is inversely related to fat oxidation (Achten and Jeukendrup, 2004). Moreover, the lactate increase above baseline (LIAB) coincides with the intensity at which fat oxidation begins to decline in adolescents (Tolfrey et al., 2010) and 
adults (Achten and Jeukendrup, 2004) and the increase in blood lactate with intensity is more pronounced in men than boys (Mahon et al., 1997). It is possible that a higher proportion of type I muscle fibres and intramuscular triacylglycerol (IMTAG) stores observed in children compared with adults may contribute to their increased ability to oxidise fat, but such data obtained from muscle biopsy in children are sparse and may also depend on training status (Bell et al., 1980; Fournier et al., 1982). Increased FFA availability and uptake during exercise in children compared with adults has also been reported (Delamarche et al., 1992), but not always confirmed (Boisseau and Delamarche, 2000; Martinez and Haymes, 1992). Although no age-related changes in carnitine palmitoyltransferase (CPT1) activity or major differences in enzyme activities of fat metabolism were observed in children compared with adults (Haralambie, 1982; Kaczor et al., 2005), the CPT/2-oxoglutarate dehydrogenase ratio of enzyme activities in skeletal muscle may be higher in children (Kaczor et al., 2005), suggesting a preferential oxidation of fat over CHO.

More recent work using stable isotope techniques indicates that children do not have an underdeveloped glycolytic flux and it is has been suggested that glycogen stores limit $\mathrm{CHO}$ oxidation. Indeed, younger, less mature boys rely more on exogenous $\mathrm{CHO}$ oxidation during exercise (Timmons et al. 2007a; see section 6.2). Although no difference in exogenous CHO oxidation was reported between 12 and 14 year old girls, this may have been due to the small difference in puberty between the two groups (Tanner 3 and 4) (Timmons et al. 2007b). These findings should be considered in the context of exercise training, however, as the early work by Eriksson et al. (1973) showed that 4 months of training increased muscle glycogen concentration in 11 to 13 year old boys and, after maximal work, blood and muscle lactate were higher and a greater reduction in muscle glycogen occurred. In a second experiment, 6 weeks of training increased succinate dehydrogenase and phosphofructokinase activities by 
30 and $83 \%$, respectively (Eriksson et al. 1973). Therefore, the capacity to store and use glycogen may increase with training in boys; there is no available direct evidence of this in girls.

\section{CHO intake: the days and hours before endurance exercise}

Manipulating $\mathrm{CHO}$ intake in the days ('CHO loading') and hours before an important exercise training session or competition allows adult athletes to commence exercise with glycogen stores sufficient to fuel the event. In adults, glycogen stores are an important source of blood glucose to provide energy for exercise and studies using invasive methods have shown that severe reductions in muscle glycogen (Bergström et al., 1967) and blood glucose derived from liver glycogen (Coyle and Coggan, 1984) are associated with the early onset of fatigue. Accordingly, elevating muscle glycogen content prior to exercise through the consumption of a high-CHO diet (CHO loading) postpones fatigue by approximately $20 \%$ in endurance events lasting more than 90 minutes, where exhaustion often coincides with critically low muscle glycogen content (Hawley et al. 1997). Carbohydrate loading and the associated glycogen supercompensation (i.e., increase above original baseline concentration) may also improve endurance performance by 2 to 3\% where a pre-determined distance is covered as quickly as possible. Conversely, there is little or no effect of elevating preexercise muscle glycogen content above normal resting values on a single exhaustive bout of high-intensity exercise lasting less than 5 minutes or for moderate-intensity running or cycling lasting 60 to 90 minutes, where substantial quantities of glycogen remain in the working muscles at the end of exercise (Hawley et al. 1997). Adult endurance athletes can achieve glycogen supercompensation without the need for the 'traditional' depletion phase (exhaustive exercise and low $\mathrm{CHO}$ diet to achieve glycogen depletion) in the days before loading, and with as little as 24 to 36 hours of high CHO intake and rest (Burke et al. 2011). 
Based on dietary recommendations for adults, young athletes may be under the impression that consuming a high-CHO diet in the days and hours before exercise will improve performance, and consequently they might $\mathrm{CHO}$ load to some degree in preparation for major events. However, the effects of $\mathrm{CHO}$ loading on glycogen supercompensation and performance in children and adolescents remain unknown, partly due to ethical issues surrounding the use of invasive procedures with young people (e.g. muscle biopsies for the determination of muscle glycogen) and side effects associated with the glycogen depletion stage of the 'traditional' CHO loading protocol (Bergström et al. 1967). In fact, the commonly held understanding that $\mathrm{CHO}$ loading can improve performance may not apply as readily to young people for various reasons. First, the relevance of $\mathrm{CHO}$ loading to youth athletes engaging in events lasting less than 90 minutes should be questioned, based on evidence from adults. Second, it appears that the physiological mechanism underpinning the effect of CHO loading on performance in adults may not translate to children due to their limited capacity to store glycogen (Eriksson et al. 1973) and utilise endogenous CHO during exercise (Timmons et al. 2007a). This suggests that children may not be able to 'supercompensate' and, even if children did exhibit an ability to increase muscle glycogen through CHO loading, they are less likely to use endogenous CHO to provide energy for exercise (see section 4). Indeed, there is evidence that adult women may not benefit from CHO loading and, like children, appear to rely to a greater extent on fat and exogenous $\mathrm{CHO}$ oxidation during exercise than adult men (Horton et al. 1998; Tarnopolsky et al. 1995; Tarnopolsky 2008). Although six days of high-CHO diet can increase muscle glycogen and cycling time to fatigue in women, the magnitude of these changes was smaller than those observed previously in men (Walker et al. 2000), with further research revealing the increase in $\mathrm{CHO}$ availability and oxidation following $\mathrm{CHO}$ loading (plus $\mathrm{CHO}$ ingestion during 
exercise) did not translate to improved performance in women (Andrews et al. 2003). When comparing men and women directly, the increase in muscle glycogen concentration and time trial performance in endurance trained men following a 4-day CHO loading regimen did not occur in women of a similar training status (Tarnopolsky et al. 1995).

Evidence that the performance-enhancing effect of CHO loading in men may not be equally effective in women implies the applicability of $\mathrm{CHO}$ loading to young athletes is questionable. However, increasing muscle glycogen stores through CHO loading may benefit male adolescents during the later stages of puberty (Tanner stage 4 and 5) when the metabolic profile is similar to that of adult men (Riddell et al. 2008; Stephens et al. 2006; Timmons et al. 2007a). Furthermore, as noted in section 4, training resulted in an increased capacity to store and use glycogen in boys (Eriksson et al. 1973); thus, young athletes who train regularly may exhibit an ability to increase their glycogen stores through $\mathrm{CHO}$ loading, with potential effects on performance. For these reasons, the interaction between training, CHO loading and exercise performance in young people warrants examination. Since it is now known that the glycogen depletion phase of $\mathrm{CHO}$ loading is not required in adults, some ethical issues associated with this research in children may no longer exist and there may be scope to study whether the effects of $\mathrm{CHO}$ loading in adults translate to young athletes.

Similar to CHO loading, research over the past three decades has supported the recommendation that adults should consume an easily digestible high CHO meal 2 to 4 hours before endurance competition. This practise replenishes liver glycogen stores (which are reduced to low values after an overnight fast), increases muscle glycogen stores and can extend endurance capacity (time to exhaustion), but does not necessarily improve time-trial performance (Chryssanthopoulos et al. 2004; Wee et al. 2005; Williams and Lamb 2008). Yet 
again, it is unclear whether the performance-enhancing effects of pre-exercise $\mathrm{CHO}$ consumption translate to young people. As with $\mathrm{CHO}$ loading, the potential for children to increase their glycogen stores needs to be examined systematically. Children do, however, have a higher capacity to use exogenous CHO (Timmons et al. 2003; 2007a); suggesting that provision of adequate pre-exercise $\mathrm{CHO}$ to maintain blood glucose concentration during exercise may be beneficial. In particular, consuming a meal rich in low glycaemic index (GI - see section 10) CHO releases glucose gradually (Jenkins et al. 1981; Ludwig et al. 1999); the attenuated postprandial glucose and insulin response maintains blood glucose concentrations during exercise, can reduce the suppression of fat oxidation that normally accompanies CHO feeding, and may improve exercise performance in adults (Burke et al. 2011). Furthermore, the blunted glucose and insulin response to meals with a low GI has been demonstrated in children and adolescents, but no effect on substrate oxidation during postprandial exercise was observed (Zakrzewski et al. 2012) and the effect on exercise performance has not been investigated. Although not all studies have supported the benefits of consuming low GI foods in the hours before exercise, this practise may be beneficial when it is difficult to consume $\mathrm{CHO}$ during exercise and in individuals who are sensitive to a hyperinsulinaemic response to CHO feedings (e.g., those with low insulin sensitivity). From a general health and well-being perspective, it is also worth mentioning that regular breakfast consumption is associated with improved health, nutrition and academic performance in young people (Rampersaud et al. 2005). In addition, exercise in the fasted state, often the alternative to consuming a high-CHO meal 2 to 4 hours before exercise, may not be a practical option for young people. Consequently, fasted exercise involving 'skipping breakfast’ may not be a feasible or healthful behaviour in young people. 
There is no doubt that further research is required to provide specific recommendations for $\mathrm{CHO}$ consumption in the days and hours before exercise in young people. Importantly, the efficacy and safety of 'CHO loading' has not been studied in children and should be considered. Rather than CHO loading to 'supercompensate', it may be preferable for young athletes to ensure that $\mathrm{CHO}$ intake in the days and hours leading up to competition is sufficient to avoid depletion of glycogen stores and, perhaps more importantly, adequate $\mathrm{CHO}$ is available to meet daily requirements. Indeed, $\mathrm{CHO}$ provides an important source of energy for growth in children, who require more energy per kilogram of body weight during physical activity than adults (Bar-Or 2001). Inadequate energy intake in combination with high energy expenditures should be avoided due to the potential consequences of negative energy balance (see section 3).

\section{CHO intake: during endurance exercise}

The majority of experimental research on CHO intake in young athletes has involved the provision of different mono- and disaccharides during exercise (see Table 3). Since CHO oxidation increases with exercise intensity, increasing glucose availability should logically help sustain a higher exercise intensity and enhance performance. The available evidence in young people has generally supported these claims through examination of performance and substrate metabolism, as discussed below. Potential mechanisms explaining the enhanced performance with $\mathrm{CHO}$ intake during exercise in adults include provision of an additional fuel source when glycogen stores become depleted, muscle glycogen sparing, prevention of low blood glucose concentrations, and effects on the central nervous system; some of which may also apply to children and depend on the characteristics of the exercise. 


\subsection{Performance}

A small number of studies have investigated the effects of exogenous CHO ingestion immediately before or during exercise on performance in young people, but have produced conflicting results. In contrast to much of the adult literature, one of the first studies in young people to examine the effects of $\mathrm{CHO}$ ingestion immediately before exercise reported no effect on performance (Hendelman et al. 1997). Three hours after a standardised breakfast, 15 year old untrained adolescent boys consumed a candy bar, fat-free fig bars or a sweetened drink (placebo) 10 min before exercise. Despite varying quantities of $\mathrm{CHO}$, the pre-exercise CHO snacks did not affect blood glucose concentration or substrate oxidation during 75 min cycling at $60 \%$ of $\mathrm{VO}_{2 \max }$ or subsequent time trial performance (Hendelman et al. 1997). However, the performance trial may have been too short (5 to 6 minutes) to detect differences due to substrate availability. Furthermore, is not possible to isolate the effects of CHO from total energy intake on performance as the snacks were not standardised for macronutrient or energy content, and participants were provided with absolute amounts of $\mathrm{CHO}$, resulting in individual variation in amounts relative to body size. Notwithstanding the short-comings of the study, it should be noted that performance times were faster in the CHO conditions (311.9 s and $316.2 \mathrm{~s}$ ) compared with the placebo (328.1 s), a difference that was not statistically significant, but may be meaningful for young athletes competing against others of a similar standard.

Subsequent work has supported the benefits of $\mathrm{CHO}$ ingestion during exercise for endurance performance in young people and suggests that the composition of the ingested CHO can affect the extent of the improvement. Compared with a placebo (water), ingestion of a 6\% glucose or $3 \%$ glucose plus $3 \%$ fructose solution during 90 min of moderate intensity exercise delayed time to exhaustion at $90 \%$ of maximal power output in boys aged 10 to 14 
years (Riddell et al. 2001). Indirect support for this finding comes from reports of reduced ratings of perceived exertion (RPE) during exercise with glucose ingestion in adolescent boys, indicating the boys felt the exercise was 'easier' (Riddell et al. 2000a). Interestingly, consuming the glucose-fructose mixed drink enhanced time to exhaustion more than glucose alone (40\% and 25\% delays, respectively) compared with water (Riddell et al. 2001). Although the authors speculated that the enhanced performance with the glucose-fructose mix may be related to the additional muscle glycogen-sparing effect of fructose, endogenous CHO oxidation (i.e., liver and muscle glycogen) did not differ between trials despite a reduced reliance on exogenous glucose sources with the fructose plus glucose drink. It is also possible that the improvement in performance with CHO intake could be due partly to a nonmetabolic mechanism. In adults, mouth rinsing can enhance performance when a high power output is required over durations of 45 to 75 min via its effects on the central nervous system (CNS), with CHO-rich pre-event meals dampening this effect (Jeukendrup and Chambers, 2010). It is interesting to note that the boys in the aforementioned Hendelman et al. (1997) study may have not benefited from the non-metabolic effects of $\mathrm{CHO}$ ingestion during exercise, as $\mathrm{CHO}$ was provided 10 min before exercise.

The finding that performance only improved in seven of twelve subjects in the glucose trial and nine out of twelve in the glucose-fructose mix trial highlights the need for future research to consider individual variation. In particular, the inclusion of 10 to 14 year olds in Tanner stages 2 to 4 (early to late-pubertal) coupled with the known effects of age and puberty on metabolism is likely to have contributed to individual variation (Timmons et al. 2007a). Future studies should also consider the performance test used, which could contribute to some of the variability; the reliability of tests to volitional exhaustion in children is not known and prolonged tests to exhaustion have a high coefficient of variation in adults 
(Jeukendrup et al. 1996). Although the order of the trials was counterbalanced, the inclusion of a habituation session has been suggested to reduce the coefficient of variation in adolescents completing a cycling time trial (Montfort-Steiger et al. 2005).

Further research is required to clarify the potential benefits of $\mathrm{CHO}$ supplementation on performance in young people, including identification of the optimal $\mathrm{CHO}$ feeding regimen (dosage, composition, timings) for peak performance, taking into consideration individual factors such as age, puberty, sex, training status and previous diet. Studies investigating reasons for between-subject variability could pave the way to a more individualised approach to $\mathrm{CHO}$ prescription. In particular, although an improvement in performance with glucose ingestion throughout exercise has been documented in women (Campbell et al. 2001); this finding requires investigation in prepubertal and adolescent girls to inform sex-specific dietary recommendations for athletic performance.

\subsection{Substrate oxidation}

The improved endurance performance with $\mathrm{CHO}$ intake in adults is attributed largely to increased $\mathrm{CHO}$ oxidation and maintenance of euglycaemia during exercise, particularly as exercise duration increases and endogenous CHO stores become depleted. Although the invasive nature of the techniques employed to quantify glycogen stores has posed ethical restrictions when considering similar research with children, stable isotope tracer techniques used in conjunction with indirect calorimetry represents a promising non-invasive method of estimating endogenous and exogenous substrate oxidation in younger age groups and has been used to examine the effects of CHO ingestion during exercise (Riddell et al. 2000a; Timmons et al. 2003; 2007a). 
In young people, $\mathrm{CHO}$ ingestion during exercise increases total $\mathrm{CHO}$ oxidation and lowers total fat oxidation when compared with a placebo, often flavoured water (Table 3). These findings have been demonstrated mainly in healthy boys aged 10 to 17 years (e.g. Riddell et al. 2000a; Timmons et al. 2007a) and may also apply to girls (Timmons et al. 2007b) and obese boys (Chu et al. 2011) although the evidence is sparse. The mechanisms responsible for the reduction in fat oxidation following $\mathrm{CHO}$ ingestion relate to the rise in insulin that inhibits lipolysis and free fatty acid (FFA) availability (Horowitz et al. 1997) and the increase in blood glucose uptake and, therefore, CHO oxidation, which inhibits the rate of FFA entry into the mitochondria (Coyle et al. 1997; Sidossis et al. 1996). During exercise, glucose supplementation increases glucose and insulin concentrations, increases CHO oxidation and suppresses fat oxidation in boys (Riddell et al. 2001; Timmons et al. 2007a). Separate examination of exogenous and endogenous substrate stores has revealed that the reduction in fat oxidation and increased exogenous $\mathrm{CHO}$ oxidation during exercise with $\mathrm{CHO}$ ingestion is accompanied by a sparing of endogenous CHO in boys (Timmons et al. 2007a). Thus, it appears that $\mathrm{CHO}$ is preferable over fat as a fuel when exogenous $\mathrm{CHO}$ is provided at a sufficient rate during exercise in young people.

Consideration of age and pubertal status is crucial when evaluating the effects of CHO ingestion during exercise in young people. Whether exercise is performed with or without CHO ingestion, boys and girls oxidise a proportionally higher amount of fat and lower amount of CHO than adults (Riddell et al. 2008; Timmons et al. 2003; 2007a; 2007b). When $\mathrm{CHO}$ is ingested during exercise, pre- and early-pubertal boys exhibit a higher rate of exogenous $\mathrm{CHO}$ oxidation, which provides a greater relative proportion of total energy, compared with adult men (Timmons et al. 2003). Interestingly, the rate of exogenous CHO oxidation in boys (Timmons et al. 2003) is similar to trained adults, who also have increased 
rates of fat oxidation during exercise (Burelle et al. 1999; Jeukendrup et al. 1997), highlighting the need to consider training status when comparing young people and adults. Independent of chronological age, advanced pubertal status reduces the contribution of exogenous $\mathrm{CHO}$ oxidation to total energy expenditure, and testosterone concentration is inversely related to exogenous CHO oxidation in males (Timmons et al. 2007a). Therefore, the age-related effects of $\mathrm{CHO}$ intake on exercise metabolism are likely attributed to puberty.

The higher exogenous $\mathrm{CHO}$ oxidation in younger and less mature boys when $\mathrm{CHO}$ is ingested during exercise is accompanied by a greater conservation of endogenous glycogen stores compared with more mature boys and adult men (Timmons et al. 2003; 2007a). Since it is unlikely that a blunted ability to oxidise $\mathrm{CHO}$ can explain the lower total $\mathrm{CHO}$ and higher fat oxidation in these boys due to their well-developed capacity to oxidise exogenous $\mathrm{CHO}$, the greater 'sparing' of endogenous $\mathrm{CHO}$ stores could indicate a reduced capacity to store muscle glycogen in younger less mature boys. Moreover, the decrease in blood glucose during the onset of exercise suggests reduced glycogen stores in boys (Riddell et al. 2001) and girls (Delamarche et al. 1994). Children may compensate for the limited glycogen stores by increasing their reliance on exogenous fuels, such as consumption of CHO snacks and beverages, when available. It has been suggested that the greater reliance on exogenous $\mathrm{CHO}$ in younger, less mature boys may be important in protecting endogenous substrates for growth and development of the musculoskeletal system and CNS. Overall, consuming exogenous $\mathrm{CHO}$ during exercise may be of particular benefit to young and less mature boys.

Dietary recommendations for young athletes should consider these findings by advocating the consumption of orally consumed $\mathrm{CHO}$ during or immediately before exercise to ensure sufficient exogenous $\mathrm{CHO}$ is available to fuel exercise in younger less mature children, 
perhaps more so than adults. Ideally, CHO recommendations should be specific to pubertal status rather than chronological age, with a reduced need to provide exogenous $\mathrm{CHO}$ as maturation progresses. Since rates of exogenous CHO oxidation in more mature 12 year old boys were similar to those of 14 year old pubertal boys, it may be sufficient to distinguish between young people in pre- and early puberty and those in mid-late puberty, rather than each of the five Tanner stages (Timmons et al. 2007a). Importantly, exogenous CHO oxidation increases with exercise duration (Timmons et al. 2003), meaning that boys competing in endurance events in particular could benefit from $\mathrm{CHO}$ ingestion during exercise. However, the direct application of this recommendation for young athletes who exercise less than 60 to 120 minutes, as used in the supporting evidence, is questionable.

Whether from the pediatric or adult literature, the majority of research on exercise metabolism has been conducted in males. Similar to boys, there is some evidence that younger less mature girls have higher fat and lower endogenous $\mathrm{CHO}$ oxidation rates during exercise compared with older adolescents (Timmons et al. 2007b). However, CHO supplementation only reduced fat oxidation in those aged 12 years, not those aged 14 years, and the balance between exogenous and endogenous $\mathrm{CHO}$ oxidation during exercise was not different between 12 and 14 year old girls. Consequently, it is possible the reported age- and maturation-related differences in exogenous $\mathrm{CHO}$ oxidation in males and the potential implications for performance may not apply to girls. Alternatively, the similarity in exogenous $\mathrm{CHO}$ oxidation reported between 12 and 14 year old girls may have been due to the small, albeit statistically significant, difference in puberty between the two groups (Tanner 3 and 4) (Timmons et al. 2007b). This is complicated further by issues related to menstrual cycle stage; all 14 year old girls were tested in the early follicular phase, but only 4 of the 12 year olds had experienced their first menstrual period and were not tested at a 
standardised time due to the sporadic nature of their menstruation. It is advisable to control for menstrual cycle stage, as variations in ovarian hormone levels throughout the menstrual cycle alter exercise metabolism in women (Oosthuyse and Bosch, 2010). Interestingly, ingestion of glucose minimises these effects and there is evidence the performanceenhancing effects of glucose ingestion during exercise are more pronounced in the luteal compared with the follicular stage (26\% vs. 19\% improvement) (Campbell et al. 2001).

Unfortunately, studies that replicate the reported findings in girls are not available, making it impossible to draw any firm conclusions based on the available evidence. Due to some of the data inconsistencies between studies including boys and girls, studies directly examining between-sex differences in the response to $\mathrm{CHO}$ supplementation in young people are needed. In adults, there is evidence that women may derive a greater benefit from $\mathrm{CHO}$ ingestion than men; women oxidise a greater relative proportion of exogenous $\mathrm{CHO}$ during endurance exercise, which spares more endogenous fuel (Campbell et al. 2001; Riddell et al. 2003). Moreover, glucose ingestion improved time trial performance by a 19 to $26 \%$ in trained women (Campbell et al. 2001), but only 7\% in trained men (Angus et al. 2000), although differences in study design mean these values cannot be compared directly. A direct comparison of trained men and women, however, reported remarkably similar metabolic responses to $\mathrm{CHO}$ supplementation, with both groups experiencing an increased plasma glucose turnover and oxidation, which suppressed fat and endogenous CHO oxidation (Wallis et al. 2006). Future studies with children and adolescents, controlling for training status and puberty, should include both boys and girls to determine possible sex-related differences to CHO supplementation during exercise to inform nutritional recommendations for athletic performance in young male and female athletes. 


\section{CHO intake: Post-exercise}

Timing of food consumption based on competition or exercise event time is important to, not only enhance exercise performance, but also improve recovery time. Consuming the correct nutrients during the period after exercise is essential for initiating the rebuilding of damaged muscle tissue and the restoration of energy reserves. Since a fundamental goal of traditional post-exercise nutrient timing is to replenish glycogen stores, $\mathrm{CHO}$ intake after exercise is critical when glycogen is depleted. Although the post-exercise period is widely considered the most important part of nutrient timing in adults (Burke et al. 2004; 2011), very few studies have examined post-exercise $\mathrm{CHO}$ intake in young people. Consequently, the evidence discussed within this section is based on studies with adults and it is important to highlight from the beginning that the findings may not apply to young people, particularly pre- and early pubertal children.

Consumption of $\mathrm{CHO}$ (or $\mathrm{CHO}$ plus protein) within 30 min of an exercise session results in higher glycogen levels than when ingestion is delayed for 2 hours (Ivy et al. 1988; 2002). When post-exercise CHO intake is proportional to body mass, men and women are able to benefit to a similar extent from faster glycogen resynthesis compared with placebo ingestion (Tarnopolsky et al. 1997). This enhanced capacity to replenish glycogen stores may allow performance to be maintained during periods of training, with post-exercise $\mathrm{CHO}$ consumption over a 7 day training period improving subsequent performance (increased time to exhaustion) compared with a placebo (Roy et al. 2002). The composition of the snack and type of CHO consumed after exercise affects the extent of glycogen synthesis. Carbohydrates with a high GI supply energy quickly for glycogen resynthesis during recovery and result in higher muscle glycogen levels 24 hours after a glycogen-depleting exercise when compared with low GI CHOs (Burke et al. 1993). Accordingly, when comparing simple sugars, it 
appears that glucose and sucrose are equally effective, whereas fructose alone (which has a lower GI) is less effective (Blom et al. 1987). Therefore, consumption of high GI CHO snacks after exercise rather than low GI $\mathrm{CHO}$ and fructose-containing snacks are recommended for adults. When considering meal composition, it is often recommended that adults should consume a mixed $\mathrm{CHO}$ and protein meal following exercise, ideally in a 3:1 CHO to protein ratio (Kerksick et al. 2008). Although glycogen synthesis rates may not necessarily be improved with the co-ingestion of protein and $\mathrm{CHO}$ compared with isoenergetic CHO ingestion (Millard-Stafford et al. 2008), the provision of protein and amino acids for muscle protein repair and promoting a more anabolic hormonal profile (Rodriguez et al. 2007) may be particularly important for growing young people. Milk may, therefore, be a convenient source of protein and $\mathrm{CHO}$ when it is not possible to consume a meal after exercise. Indeed, glycogen repletion is similar when CHOs are consumed in the form of solids and liquids (Burke et al. 2004) and liquids are sometimes preferred by athletes immediately after exercise for practical reasons. However, caution should be taken when translating such findings to young people, as the efficacy of post-exercise fluid 'supplements' has not been studied in children and adolescents. This practice might be best avoided in younger populations, who can gain the same benefits from consuming a post-exercise $\mathrm{CHO}$ and protein as part of a well-balanced diet.

Based on the available evidence in adults, the joint position stand of the American College of Sports Medicine and American Dietetic Association (2009) recommends the consumption of approximately 1.0 to $1.5 \mathrm{~g} \cdot \mathrm{kg} \cdot$ body weight ${ }^{-1}$ of $\mathrm{CHO}$ during the first $30 \mathrm{~min}$ and again every 2 hours for 4 to 6 hours to replace glycogen stores (American Dietetic Association, 2009). These recommendations are particularly important when the time between two training sessions is less than 8 hours or sessions are very prolonged (Berardi et al. 2006; Ivy et al. 
2002). It is unnecessary for athletes who rest one or more days between intense training sessions to practice nutrient timing provided sufficient $\mathrm{CHO}$ is consumed during the 24 hour period after the exercise bout (Burke et al. 1996). For instance, glycogen stores would be depleted to a large extent following a marathon, but these athletes are not likely to perform another race or exercise session the same day; CHO intake after exercise would be more important for triathletes training for durations of around 60 to 90 min twice a day. When considering whether the benefits of post-exercise $\mathrm{CHO}$ intake apply to children and adolescents, age and maturation-related changes in metabolism must be considered. As discussed in sections 4 and 5, the lower muscle endogenous CHO stores in younger, less mature children may indicate that 'supercompensation' of muscle glycogen is not possible. Alternatively, the effects of post-exercise $\mathrm{CHO}$ intake may actually be enhanced in this population if glycogen levels can be enhanced to some degree; boys may be able to increased muscle glycogen concentration and use more muscle glycogen during maximal exercise in response to training (Eriksson et al. 1973). Nevertheless, consuming a meal or snack after exercise may be important for all athletes, regardless of age, to meet daily $\mathrm{CHO}$ and energy balance goals. Although child and adolescent athletes do not typically engage in more than one intense training session per day, there may be occasions where they participate in multiple events in one day (e.g., track and field meetings) and it may be preferable for endurance athletes training every day (e.g., distance runners, swimmers, cyclists) to consume CHO within 30 min of training to aid recovery. Indeed, CHO supplementation during exercise in boys can diminish post-exercise physiologic stress and attenuate the immediate exercise-induced increase in immune counts in boys, indicating improved immune function (Timmons et al. 2004). Research investigating the effect of post-exercise CHO intake on recovery, fuel stores and subsequent performance in young people is much needed. 


\section{Short duration high intensity exercise and skill performance}

Children typically engage in very short bursts of intense physical activity interspersed with varying intervals of low and moderate intensity during both habitual free-play (Bailey et al. 1995) and various team sports, rather than continuous bouts of 1 to 2 hours that have been studied in much of the research discussed. Since CHO oxidation provides the majority of ATP during higher intensity exercise where the glycolytic energy pathway predominates, logic suggests that low $\mathrm{CHO}$ availability might limit high intensity exercise performance, as reported in adults (Maughan et al. 1997). Carbohydrate ingestion during exercise can improve performance when the exercise is of high intensity $\left(75 \% \mathrm{VO}_{2 \max }\right)$ and relatively short duration ( $<1$ hour), and it has become clear that the underlying mechanism for this is not metabolic, but may reside in the CNS. Indeed, undigested CHO mouth rinses have been shown to result in similar performance improvements (Jeukendrup and Chambers, 2010).

Again, data in young people are confined to only a few studies with inconsistent findings. When boys ingested CHO 30 min before repeated Wingate anaerobic tests (WAnT), peak power and mean power were not different compared with placebo ingestion, indicating no improvement in performance. Post-exercise glucose concentration and blood lactate concentration were also unaffected, despite higher pre-exercise glucose concentration in the CHO trial (Marjerrison et al. 2007). Similarly, CHO ingestion immediately before and during exercise did not affect sprint times during a modified version of the Loughborough Intermittent Shuttle Test in team game players aged 12 to 14 years (Phillips et al. 2010), with follow-up studies showing no effect of the concentration of CHO consumed (Phillips et al. 2012a) or a CHO (maltodextrin) compared with a placebo gel (Phillips et al. 2012b) on 15 second sprint time. Likewise, during a 90 minute basketball-specific training session in 14 to 15 year old male basketball players, sprint performance was not influenced by ad libitum 
consumption of an $8 \%$ carbohydrate solution compared with no fluid ingestion (Carvalho et al. 2011). However, it may be noteworthy that the 6\% CHO-electrolyte drink improved time to exhaustion by $24 \%$ (Phillips et al. 2010). In a separate study, the same group found a 6\% CHO-electrolyte solution improved time to exhaustion during intermittent exercise by $34 \%$ compared with a 10\% solution (Phillips et al. 2012a). Furthermore, a CHO (maltodextrin) gel increased intermittent endurance capacity by 21\% (Phillips et al. 2012b). This indicates that supplementation benefitted at least some of the players, with the greatest benefits from consuming a $6 \%$ solution. Overall, the limited evidence suggests that pre-exercise $\mathrm{CHO}$ ingestion may improve intermittent endurance capacity, but not sprint performance in adolescent boys. Again, it is not possible to make firm conclusions based on the available evidence, which is limited to a few studies that have not typically included girls.

\section{Sports drinks and hydration}

Despite the paucity of literature on exogenous $\mathrm{CHO}$ ingestion during exercise and performance in young athletes, evidence does suggest that adding CHO to sports drinks may be beneficial for maintaining hydration (please refer to Chapter ?? 'Hydration for the young athlete') $* * *$ Note for Chad to update when editing our chapter and making a link to another author's chapter***. Adding flavour, $\mathrm{CHO}$ and sodium chloride $(\mathrm{NaCl})$ to drinks has been used as a strategy to improve the palatability of sports drinks, increase voluntary fluid intake and help maintain hydration during exercise. Compared with unflavoured water, voluntary fluid intake increased by $45 \%$ with flavoured water and almost doubled with a $6 \% \mathrm{CHO}$ and $18 \mathrm{mmol} \cdot \mathrm{L}^{-1} \mathrm{NaCl}$ drink in boys (Wilk and Bar-Or 1996). Consequently, while flavouring water reduced voluntary dehydration, the further addition of $\mathrm{CHO}$ and $\mathrm{NaCl}$ prevented it altogether. Similar findings were observed in trained, heat-acclimatised boys who experienced higher sweating rates during prolonged exercise (Rivera-Brown et al. 1999). 
These studies have focused on exercise in hot humid conditions and have typically used three hour exercise protocols consisting of four 20-min cycling bouts at 50 to $60 \%$ maximal oxygen uptake (interspersed with 25 min rest periods). When using a different exercise protocol more closely reflecting real-life situations (a time trial run followed the steady-state exercise bouts), voluntarily fluid consumption, hydration and time to exhaustion were similar regardless of whether unflavoured water, flavoured water or flavoured water with $\mathrm{CHO}$ and $\mathrm{NaCl}$ was provided to heat-acclimatised adolescent male runners (Wilk et al. 2010). Furthermore, in non-acclimatised girls exercising in the heat, voluntary drinking was enhanced with flavoured compared with unflavoured water regardless of combination with $\mathrm{CHO}$ and $\mathrm{NaCl}$, but hydration was promoted to a greater extent with the drink containing CHO and $\mathrm{NaCl}$ (Wilk et al. 2007). Similarly, there was a tendency towards a lower hypohydration and greater fluid retention with the consumption of a $\mathrm{CHO}$ plus $\mathrm{NaCl}$ drink in

trained, heat-acclimatised girls with high sweating rates, although voluntary dehydration was not prevented completely (Rivera-Brown et al. 2008). Based on these studies, it would appear that voluntary dehydration may be reduced to some extent by drinking a CHO-electrolyte drink in both girls and boys, but it is not possible to determine the independent effects of $\mathrm{CHO}$ and $\mathrm{NaCl}$. Caution is recommended when interpreting these findings, based on prolonged exercise ( 4 x 20-min bouts with 25 min rest periods) in hot humid conditions. For many young people training for shorter periods $(<90 \mathrm{~min})$ in temperate conditions, the promotion of these drinks may lead to unnecessary overconsumption of sugary drinks (see section 10).

\section{Health, glycaemic index and insulin sensitivity}

Maintenance of good health is essential for disease prevention, to promote continued wellness throughout life and for normal growth and development. Since habitual diet has a 
considerable impact on health, it is important to consider CHO intake recommendations for exercise performance alongside any potential health consequences of the practices advocated. This is particularly important for children and adolescents as they progress through puberty and develop lifestyle behaviours that can affect future health. Specifically, recommendations for $\mathrm{CHO}$ intake in young people may require special consideration, as insulin is a key hormone stimulating glucose uptake and regulating glycogen metabolism during rest and exercise, and the pubertal transition from Tanner stage 1 to 3 is associated with a $32 \%$ reduction in insulin sensitivity with concomitant increases in fasting glucose, insulin and the acute response to glucose, which recovers by Tanner stage 5 (Goran and Gower, 2001). Consequently, caution should be exercised when prescribing high $\mathrm{CHO}$ diets or ' $\mathrm{CHO}$ loading' and high GI foods to young people in the pre- to mid stages of puberty.

Despite potential health concerns of prescribing specific diets to young people, the available evidence suggests that dramatic changes in $\mathrm{CHO}$ and fat intakes do not affect glucose and lipid metabolism adversely in the short term; most participants have been healthy non-obese young people, meaning that the findings are likely to apply to many young athletes. During a 7 day high-CHO diet (60\% CHO, 25\% fat) and low-CHO diet (30\% CHO, 55\% fat), prepubertal children (Tanner stage 1) and adolescents (Tanner stage 4 and 5) adapted rapidly by adjusting $\mathrm{CHO}$ and fat oxidation to macronutrient intake, with only minor changes in parameters of glucose metabolism (Sunehag et al. 2002). Interestingly, acute consumption of a high-CHO diet did not affect insulin sensitivity adversely in these children and adolescents, whereas insulin sensitivity actually improved when the adolescents changed from a low-CHO to high-CHO diet. Similar findings were observed when energy intake was adjusted for the maintenance of energy balance (estimated from individual basal metabolic rate), with healthy non-obese children and adolescents increasing their $\mathrm{CHO}$ oxidation during a high-CHO diet 
and fat oxidation during a high-fat diet (Treuth et al. 2003). However, the boys exhibited more pronounced changes in substrate oxidation than the girls, indicating boys may adapt more readily to changes in diet composition (Treuth et al. 2003). Unlike lean adolescents, obese adolescents failed to increase insulin sensitivity during the high-CHO diet, resulting in increased insulin secretion to maintain normal blood glucose levels (Sunehag et al. 2005). Consequently, high CHO-diets may not be suitable for certain populations, including overweight children and possibly girls.

When considering $\mathrm{CHO}$ ingestion during exercise, the presence of certain health conditions must be considered, particularly insulin dependent diabetes mellitus (IDDM) and obesity. Although no difference in substrate oxidation between boys with and without IDDM occurred when a placebo was given during exercise, exogenous glucose oxidation was impaired in boys with IDDM when glucose was ingested despite two- to threefold higher blood glucose and plasma insulin concentrations than the healthy controls. Glucose ingestion did, however, spare endogenous glycogen stores to a similar extent in both groups (Riddell et al. 2000b). Moreover, glucose ingestion equal to total-CHO utilisation attenuated the drop in blood glucose, reducing the likelihood of hypoglycaemia during moderate intensity exercise in boys with IDDM (Riddell et al. 2000b). Overweight young people may also have specific nutritional needs due to their altered metabolism, including a greater reliance on $\mathrm{CHO}$ oxidation during exercise (McMurray and Hosick 2011). The suppression of whole body fat oxidation during exercise with CHO ingestion (vs. placebo) is likely to be counterproductive for obese children trying to maximise fat oxidation and weight management through regular physical activity (Chu et al. 2011). Moreover, consumption of sugar-sweetened beverages, including sports drinks, energy drinks, lemonade, and other fruit drinks, has been linked to excess weight gain in children and adults (Malik et al. 2006). Indeed, it would not be 
advisable to recommend $\mathrm{CHO}$ supplementation during exercise in overweight children if this adds to their total daily energy intake. It is also crucial that young people are aware of the difference between sports and energy drinks and do not consume these drinks on a regular basis as part of their diet. Sports drinks may be recommended for fuel and hydration before during and after prolonged exercise in hot humid conditions (see section 9), but are categorised as 'sugar-sweetened beverages'. Thus, regular consumption of sports drinks for most young athletes is likely to be unwarranted and could result in the overconsumption of sugar. Energy drinks specifically are not recommended due to the health risks associated with many of the ingredients, related to cardiovascular disease and bone mineralisation (Seifert et al. 2011).

Rather than the total amount of CHO in the diet, the 'quality' or GI of the CHO may have greater relevance for health. The concept of GI was introduced as a method of classifying different CHO-rich foods according to their effect on postprandial glycaemia and is defined as the incremental area under the two hour blood glucose curve following ingestion of $50 \mathrm{~g}$ available $\mathrm{CHO}$ as a percentage of the corresponding area following an equivalent amount of CHO from a standard reference product (glucose or white bread) (Jenkins et al. 1981). Foods classified as HGI include refined grain products, white bread and potato, whereas LGI foods include whole grain products, legumes and fruits. There is now a large body of evidence providing robust support for low GI diets in the prevention of obesity, diabetes, and cardiovascular disease in adults (Brand-Miller et al. 2009) with similar findings emerging in young people (Fajcsak et al. 2008; Rovner et al. 2009; Rouhani et al. 2013). Therefore, although high GI snacks may be recommended after exercise to promote the replenishment of muscle glycogen stores in adults, caution should be exercised when promoting the regular 
consumption of high GI foods in young people. This is particularly pertinent in adolescents within the mid-pubertal stages who are characterised by a reduction in insulin sensitivity.

Finally, it should be highlighted that many of the reviewed studies within the pediatric literature refer to 'CHO supplementation' rather than meals or snacks. In general, the use of dietary supplements is not advocated for children or adolescents. Young athletes who consume sports drinks and energy drinks for their perceived physiological benefits may not be aware of the potential risks (e.g., high sugar content) and, in many cases, specific health benefits from nutritional supplements and drinks may be better achieved through appropriate consumption of a nutritious diet. Regarding $\mathrm{CHO}$ supplementation specifically, glucose drinks consumed during prolonged exercise when it is not possible to consume food may be beneficial. However, pre- and post-exercise CHO needs can be met by consuming food and drink as part of a healthy balanced diet. In particular, the benefits and efficacy of 'recovery drinks' for young people have not been studied, perhaps partly due to the concerns linked with promoting this practice in children.

\section{Summary}

Nutrition, including adequate CHO intake, is essential for the health and performance of young athletes. Since young athletes have physiological and metabolic characteristics that distinguish them from adults, nutritional recommendations must be tailored to the age and pubertal stage of the athlete. Unfortunately, most of the knowledge on the CHO needs of athletes is informed by evidence from adult-based research. The development of specific recommendations for young athletes is difficult due to the lack of child-specific evidence, which is further complicated by the dietary intake required for growth and development in conjunction with that required for training and competition. Although many unanswered 
questions remain concerning $\mathrm{CHO}$ needs of the young athlete, it is possible to make some general recommendations.

In terms of the overall diet, $\mathrm{CHO}$ should contribute to the majority of energy intake, which must be high enough to support growth and maturation whilst fuelling the additional physical activity in young athletes. For child and adolescent athletes, $\mathrm{CHO}$ is also an important fuel for high intensity exercise. The Dietary Guidelines for Americans (2010) for energy intake and the AMDR values for CHO intake may provide useful guidance in calculating agespecific CHO needs in relation to physical activity level. Based on the current evidence, some authors have also attempted to make general recommendations for $\mathrm{CHO}$ intake in young athletes; for example, at least $50 \%$ of total daily energy intake (Petrie et al. 2004). Decrements in exercise performance, fatigue and changes in body composition may serve as useful indicators that $\mathrm{CHO}$ intake may not be adequate. Given the tendency of adolescent girls to limit their daily energy intake, attention should be directed to female adolescent athletes to ensure that $\mathrm{CHO}$ needs are met daily and energy balance is maintained.

Timing of $\mathrm{CHO}$ consumption in relation to training and competition requires examination in young athletes. Currently, evidence on CHO loading in young athletes is not available. During exercise, drinks containing $\mathrm{CHO}$ could be considered for young athletes engaged in endurance exercise due to the preferential use of exogenous $\mathrm{CHO}$ in younger athletes in the pre- or early- pubertal stages. Although CHO-electrolyte drinks can minimise voluntary dehydration, there are health concerns associated with excessive consumption of such sugary beverages. Therefore, a healthy, balanced diet in line with the AMDR for total and CHO derived energy would be sufficient to fuel exercise for most young athletes. More research with young athletes is needed to inform specific recommendations for $\mathrm{CHO}$ intake and timing 
in relation to exercise, including dosage and composition, and the efficacy of exogenous CHO intake in sport-specific situations (e.g. cycling, running, team sports). In adults, the restoration of muscle and liver glycogen is a fundamental goal of recovery between training sessions or competitive events; this requires examination in children and adolescents. Most dietary CHO should be from complex low GI sources (e.g. unsweetened porridge, wholegrain bread, wholegrain pasta, brown rice, lentils), with limited quantities of simple sugars and high GI CHO, but easily-digestible high GI foods may provide a useful source of CHO in the hours before and immediately after exercise; another area warranting examination in young athletes. Undoubtedly, research that can address such issues is crucial to inform $\mathrm{CHO}$ recommendations for young athletes in terms of both total daily intakes and in relation to exercise timing (before, during and after exercise). Providing well-informed recommendations for young athletes would be valuable in ensuring the maintenance of overall health and to enhance exercise performance during these important years of growth and maturation. 


\section{References}

Achten, J., Jeukendrup, A.E. 2004. Relation between plasma lactate concentration and fat oxidation rates over a wide range of exercise intensities. International Journal of Sports Medicine 25:32-7.

American Dietetic Association; Dieticians of Canada; American College of Sports Medicine, Rodriguez, N.R, Di Marco, N.M., Langley, S. 2009. American College of Sports Medicine position stand. Nutrition and athletic performance. Medicine and Science in Sports and Exercise 41:709-31

Andrews, J.L., Sedlock, D.A., Flynn, M.G., Navalta, J.W., Ji, H. 2003. Carbohydrate loading and supplementation in endurance-trained women runners. Journal of Applied Physiology 95:584-90.

Angus, D.J., Hargreaves, M., Dancey, J., Febbraio, M.A. 2000. Effect of carbohydrate or carbohydrate plus medium-chain triglyceride ingestion on cycling time trial performance. Journal of Applied Physiology 88:113-9.

Bailey, R.C., Olson, J., Pepper, S.L., Porszasz, J., Barstow, T.J., Cooper, D.M. 1995. The level and tempo of children's physical activities: an observational study. Medicine and Science in Sports and Exercise 27:1033-41.

Bar-Or, O. 2001. Nutritional considerations for the child athlete. Canadian Journal of Applied Physiology 26 Suppl:S186-91.

Bell, R.D., MacDougall, J.D., Billeter, R., Howald, H. 1980. Muscle fiber types and morphometric analysis of skeletal muscle in six-year-old children. Medicine and Science in Sports and Exercise 12:28-31.

Berardi, J.M., Price, T.B., Noreen, E.E., Lemon, P.W. 2006. Postexercise muscle glycogen recovery enhanced with a carbohydrate-protein supplement. Medicine and Science in Sports and Exercise 38:1106-13.

Berg, A., Kim, S.S., Keul, J. 1986. Skeletal muscle enzyme activities in healthy young subjects. International Journal of Sports Medicine 7:236-9.

Bergström, J., Hermansen, L., Hultman, E., Saltin, B. 1967. Diet, muscle glycogen and physical performance. Acta Physiologica Scandinavica 71:140-50.

Blom, P.C., Høstmark, A.T., Vaage, O., Kardel, K.R., Maehlum, S. 1987. Effect of different post-exercise sugar diets on the rate of muscle glycogen synthesis. Medicine and Science in Sports and Exercise 19:491-6.

Boisseau, N., Delamarche, P. 2000. Metabolic and hormonal responses to exercise in children and adolescents. Sports Medicine 30:405-22.

Brand-Miller, J., McMillan-Price, J., Steinbeck, K., Caterson, I. 2009. Dietary glycemic index: health implications. Journal of the American College of Nutrition 28:S446-9. 
Burelle, Y., Péronnet, F., Charpentier, S., Lavoie, C., Hillaire-Marcel, C., Massicotte, D. 1999. Oxidation of an oral [13C]glucose load at rest and prolonged exercise in trained and sedentary subjects. Journal of Applied Physiology 86:52-60.

Burke, L.M., Hawley, J.A., Wong, S.H., Jeukendrup, A.E. 2011. Carbohydrates for training and competition. Journal of Sports Science 29:S17-27.

Burke, L.M., Kiens, B, Ivy JL. Carbohydrates and fat for training and recovery. 2004. Journal of Sports Science 22:15-30.

Burke, L.M., Collier, G.R., Davis, P.G., Fricker, P.A., Sanigorski, A.J., Hargreaves, M. 1996. Muscle glycogen storage after prolonged exercise: effect of the frequency of carbohydrate feedings. American Journal of Clinical Nutrition 64:115-9.

Burke, L.M., Collier, G.R., Beasley, S.K., Davis, P.G., Fricker, P.A., Heeley, P., Walder, K., Hargreaves, M. 1995. Effect of coingestion of fat and protein with carbohydrate feedings on muscle glycogen storage. Journal of Applied Physiology 78:2187-92.

Burke, L.M., Collier, G.R., Hargreaves, M. 1993. Muscle glycogen storage after prolonged exercise: effect of the glycemic index of carbohydrate feedings. Journal of Applied Physiology 75:1019-23.

Campbell, S.E., Angus, D.J., Febbraio, M.A. 2001. Glucose kinetics and exercise performance during phases of the menstrual cycle: effect of glucose ingestion. American Journal of Physiology Endocrinology and Metabolism 281:E817-25.

Carvalho, P., Oliveira, B., Barros, R., Padrão, P., Moreira, P., Teixeira, V.H. 2011. Impact of fluid restriction and ad libitum water intake or an $8 \%$ carbohydrate-electrolyte beverage on skill performance of elite adolescent basketball players. International journal of sport nutrition and Exercise Metabolism 21:214-21.

Chen, J.D., Wang, J.F., Zhao, Y.W., Jiao, Y., Hou, X.Y. 1989. Nutritional problems and measures in elite and amateur athletes. American Journal of Clinical Nutrition 49:1084-89.

Chryssanthopoulos, C., Williams, C., Nowitz, A., Bogdanis, G. 2004. Skeletal muscle glycogen concentration and metabolic responses following a high glycaemic carbohydrate breakfast. Journal of Sports Sciences 22:1065-71.

Chu, L., Riddell, M.C., Takken, T., Timmons, B.W. 2011. Carbohydrate intake reduces fat oxidation during exercise in obese boys. European Journal of Applied Physiology 111:313541.

Coyle, E.F., Jeukendrup, A.E., Wagenmakers, A.J., Saris, W.H. 1997. Fatty acid oxidation is directly regulated by carbohydrate metabolism during exercise. American Journal of Physiology 273:E268-75.

Coyle, E.F., Coggan, A.R. 1984. Effectiveness of carbohydrate feeding in delaying fatigue during prolonged exercise. Sports Medicine 1:446-458. 
Delamarche, P., Gratas-Delamarche, A., Monnier, M., Mayet, M.H., Koubi, H.E., Favier, R. 1994. Glucoregulation and hormonal changes during prolonged exercise in boys and girls. European Journal of Applied Physiology and Occupational Physiology 68:3-8.

Delamarche, P., Monnier, M., Gratas-Delamarche, A., Koubi, H.E., Mayet, M.H., Favier, R. 1992. Glucose and free fatty acid utilization during prolonged exercise in prepubertal boys in relation to catecholamine responses. European Journal of Applied Physiology and Occupational Physiology 65:66-72.

Eriksson BO. Muscle metabolism in children-a review. 1980. Acta Physiologica Scandinavica Supplement 283:20-8.

Eriksson, O., Saltin, B.1974. Muscle metabolism during exercise in boys aged 11 to 16 years compared to adults. Acta Paediatrica Belgica 28 Suppl.: 257-65.

Eriksson, B.O., Gollnick, P.D., Saltin, B. 1973. Muscle metabolism and enzyme activities after training in boys 11-13 years old. Acta Physiologica Scandinavica 87:485-97.

Fajcsak, Z., Gabor, A., Kovacs, V., Martos, E. 2008. The effects of 6-week low glycemic load diet based on low glycemic index foods in overweight/obese children--pilot study. Journal of the American College of Nutrition 27:12-21.

Foricher, J.M., Ville, N., Gratas-Delamarche, A., Delamarche, P. 2003. Effects of submaximal intensity cycle ergometry for one hour on substrate utilisation in trained prepubertal boys versus trained adults. Journal of Sports Medicine and Physical Fitness 43:36-43.

Fournier, M., Ricci, J., Taylor, A.W., Ferguson, R.J., Montpetit, R.R., Chaitman, B.R. 1982. Skeletal muscle adaptation in adolescent boys: sprint and endurance training and detraining. Medicine and Science in Sports and Exercise 14:453-6.

Goran, M.I., Gower, B.A. 2001. Longitudinal study on pubertal insulin resistance. Diabete. 50:2444-50.

Haralambie, G. 1982. Enzyme activities in skeletal muscle of 13-15 years old adolescents. Bulletin Européen de Physiopathologie Respiratoire 18:65-74.

Haralambie, G. 1979. Skeletal muscle enzyme activities in female subjects of various ages. Bulletin Européen de Physiopathologie Respiratoire 15:259-68.

Hawley, J.A., Schabort, E.J., Noakes, T.D., Dennis, S.C. 1997. Carbohydrate-loading and exercise performance. An update. Sports Medicine 24:73-81.

Hendelman, D.L., Ornstein, K., Debold, E.P., Volpe, S.L., Freedson, P.S. 1997. Preexercise feeding in untrained adolescent boys does not affect responses to endurance exercise or performance. International Journal of Sport Nutrition 7:207-18.

Horowitz, J.F., Mora-Rodriguez, R., Byerley, L.O., Coyle, E.F. 1997. Lipolytic suppression following carbohydrate ingestion limits fat oxidation during exercise. American Journal of Physiology. 273:E768-75. 
Horton, T.J., Pagliassotti, M.J., Hobbs, K., Hill, J.O. 1998. Fuel metabolism in men and women during and after long-duration exercise. Journal of Applied Physiology 85:1823-32.

Institute of Medicine. 2002. Dietary Reference Intakes for Energy, Carbohydrate, Fiber, Fat, Fatty Acids, Cholesterol, Protein, and Amino Acids. Washington (DC): The National Academies Press.

Ivy, J.L., Goforth, H.W. Jr, Damon, B.M., McCauley, T.R., Parsons, E.C., Price, T.B. 2002. Early postexercise muscle glycogen recovery is enhanced with a carbohydrate-protein supplement. Journal of Applied Physiology 93:1337-44.

Ivy, J.L., Katz, A.L., Cutler, C.L., Sherman, W.M., Coyle, E.F. 1988. Muscle glycogen synthesis after exercise: effect of time of carbohydrate ingestion. Journal of Applied Physiology 64:1480-5.

Jenkins, D.J., Wolever, T.M., Taylor, R.H., Barker, H., Fielden, H., Baldwin, J.M., Bowling, A.C., Newman, H.C., Jenkins, A.L., Goff, D.V. 1981. Glycemic index of foods: a physiological basis for carbohydrate exchange. American Journal of Clinical Nutrition34:362-6.

Jeukendrup, A.E., Chambers, E.S. 2010. Oral carbohydrate sensing and exercise performance. Current Opinion in Clinical Nutrition and Metabolic Care 13:447-51.

Jeukendrup, A.E., Mensink, M., Saris, W.H, Wagenmakers AJ. 1997. Exogenous glucose oxidation during exercise in endurance-trained and untrained subjects. Journal of Applied Physiology 82:835-40.

Jeukendrup, A., Saris, W., Brouns, F, Kester, A. 1996. A new validated endurance performance test. Medicine and Science in Sports and Exercise 28:266-70.

Kaczor, J.J., Ziolkowski, W., Popinigis, J., Tarnopolsky, M.A. 2005. Anaerobic and aerobic enzyme activities in human skeletal muscle from children and adults. Pediatric Research 57:331-5.

Kerksick, C., Harvey, T., Stout, J., Campbell, B., Wilborn, C., Kreider, R., Kalman, D., Ziegenfuss, T., Lopez, H., Landis, J., Ivy, J.L., Antonio, J. 2008. International Society of Sports Nutrition position stand: nutrient timing. Journal of the International Society of Sports Nutrition 5:17.

Leblanc, J.C., Le Gall, F., Grandjean, V. and Verger, P. 2002. Nutritional intake of French soccer players at the Clairefontaine training center. International Journal of Sports Nutrition and Exercise Metabolism 12:268-80.

Ludwig, D.S., Majzoub, J.A., Al-Zahrani, A., Dallal, G.E., Blanco, I., Roberts, S.B. 1999. High glycemic index foods, overeating, and obesity. Pediatrics103:E26.

Mácek, M., Vávra, J., Novosadová, J. 1976. Prolonged exercise in prepubertal boys. I. Cardiovascular and metabolic adjustment. European Journal of Applied Physiology and Occupational Physiology 35:291-8. 
Mahon, A.D., Duncan, G.E., Howe, C.A., Del Corral, P. 1997. Blood lactate and perceived exertion relative to ventilatory threshold: boys versus men. Medicine and Science in Sports and Exercise 29:1332-7.

Malik, V.S., Schulze, M.B., Hu, F.B. 2006. Intake of sugar-sweetened beverages and weight gain: a systematic review. American Journal of Clinical Nutrition 84:274-88.

Malina, R.M. 2010. Early sport specialization: roots, effectiveness, risks. Current Sports Medicine Reports 9(6):364-71.

Manore, M.M. 2002. Dietary recommendations and athletic menstrual dysfunction. Sports Medicine 32(14):887-901.

Marjerrison, A.D., Lee, J.D., Mahon, A.D. 2007. Preexercise carbohydrate consumption and repeated anaerobic performance in pre- and early-pubertal boys. International Journal of Sport Nutrition and Exercise Metabolism 17:140-51.

Martinez, L.R., Haymes, E.M. 1992. Substrate utilization during treadmill running in prepubertal girls and women. Medicine and Science in Sports and Exercise 24:975-83.

Martinsen, M., Sundgot-Borgen, J. 2013. Higher prevalence of eating disorders among adolescent elite athletes than controls. Medicine and Science in Sports and Exercise 45:118897.

Maughan, R.J., Greenhaff, P.L., Leiper, J.B., Ball, D., Lambert, C.P., Gleeson, M. 1997. Diet composition and the performance of high-intensity exercise. Journal of Sports Science $15: 265-75$

McMurray, R.G., Hosick, P.A. 2011. The interaction of obesity and puberty on substrate utilization during exercise: a gender comparison. Pediatric Exercise Science 23:411-31.

Millard-Stafford, M., Childers, W.L., Conger, S.A., Kampfer, A.J., Rahnert, J.A. 2008. Recovery nutrition: timing and composition after endurance exercise. Current Sports Medicine Reports 7:193-201.

Montfort-Steiger, V., Williams, C.A., Armstrong, N. 2005. The reproducibility of an endurance performance test in adolescent cyclists. European Journal of Applied Physiology 94:618-25.

Montoye, H.J. 1982. Age and oxygen utilization during submaximal treadmill exercise in males. Journal of Gerontology 37:396-402.

Oosthuyse, T., Bosch, A.N. 2010. The effect of the menstrual cycle on exercise metabolism: implications for exercise performance in eumenorrhoeic women. Sports Medicine 40:207-27.

Phillips, S.M., Turner, A.P., Sanderson, M.F., Sproule, J. 2012a. Beverage carbohydrate concentration influences the intermittent endurance capacity of adolescent team games players during prolonged intermittent running. European Journal of Applied Physiology112:1107-16. 
Phillips, S.M., Turner, A.P., Sanderson, M.F., Sproule, J. 2012b. Carbohydrate gel ingestion significantly improves the intermittent endurance capacity, but not sprint performance, of adolescent team games players during a simulated team games protocol. European Journal of Applied Physiology 112:1133-41.

Phillips, S.M., Turner, A.P., Gray, S., Sanderson, M.F., Sproule, J. 2010. Ingesting a 6\% carbohydrate-electrolyte solution improves endurance capacity, but not sprint performance, during intermittent, high-intensity shuttle running in adolescent team games players aged 1214 years. European Journal of Applied Physiology 109:811-21.

Rampersaud, G.C., Pereira, M.A., Girard, B.L., Adams, J., Metzl, J.D. 2005. Breakfast habits, nutritional status, body weight, and academic performance in children and adolescents. Journal of the American Dietetic Association 105:743-60.

Riddell, M.C., Jamnik, V.K., Iscoe, K.E., Timmons, B.W., Gledhill, N. 2008. Fat oxidation rate and the exercise intensity that elicits maximal fat oxidation decreases with pubertal status in young male subjects. Journal of Applied Physiology 105:742-8.

Riddell, M.C., Partington, S.L., Stupka, N., Armstrong, D., Rennie, C., Tarnopolsky, M.A. 2003. Substrate utilization during exercise performed with and without glucose ingestion in female and male endurance trained athletes. International Journal of Sport Nutrition and Exercise Metabolism 13:407-21.

Riddell, M.C., Bar-Or, O., Wilk, B., Parolin, M.L., Heigenhauser, G.J. 2001. Substrate utilization during exercise with glucose and glucose plus fructose ingestion in boys ages 1014 yr. Journal of Applied Physiology 90:903-11.

Riddell, M.C., Bar-Or, O., Schwarcz, H.P., Heigenhauser, G.J. 2000a. Substrate utilization in boys during exercise with [13C]-glucose ingestion. European Journal of Applied Physiology 83:441-8.

Riddell, M.C., Bar-Or, O., Hollidge-Horvat, M., Schwarcz, H.P., Heigenhauser, G.J. 2000b. Glucose ingestion and substrate utilization during exercise in boys with IDDM. Journal of Applied Physiology 88:1239-46.

Rivera-Brown, A.M., Ramírez-Marrero, F.A., Wilk, B., Bar-Or, O. 2008. Voluntary drinking and hydration in trained, heat-acclimatized girls exercising in a hot and humid climate. European Journal of Applied Physiology 103:109-16.

Rivera-Brown, A.M., Gutiérrez, R., Gutiérrez, J.C., Frontera, W.R., Bar-Or O. 1999. Drink composition, voluntary drinking, and fluid balance in exercising, trained, heat-acclimatized boys. Journal of Applied Physiology 86:78-84.

Robinson, S. 1938. Experimental studies of physical fitness in relation to age. Arbeitsphysiologie 10:251-323.

Rodriguez, N.R., Vislocky, L.M., Gaine, P.C. 2007. Dietary protein, endurance exercise, and human skeletal-muscle protein turnover. Current Opinion in Clinical Nutrition and Metabolic Care 10:40-5. 
Rouhani, M.H., Salehi-Abargouei, A., Azadbakht, L.. 2013 Effect of glycemic index and glycemic load on energy intake in children. Nutrition 29:1100-5.

Rowland, T.W., Rimany, T.A. 1995. Physiological responses to prolonged exercise in premenarcheal and adult females. Pediatric Exercise Science 7:183-91.

Roy, B.D., Luttmer, K., Bosman, M.J., Tarnopolsky, M.A. 2002. The influence of postexercise macronutrient intake on energy balance and protein metabolism in active females participating in endurance training. International Journal of Sport Nutrition and Exercise Metabolism 12:172-88.

Rovner, A.J., Nansel, T.R., Gellar, L. 2009. The effect of a low-glycemic diet vs a standard diet on blood glucose levels and macronutrient intake in children with type 1 diabetes. Journal of the American Dietetic Association 109:303-7.

Seifert, S.M., Schaechter, J.L., Hershorin, E.R., Lipshultz, S.E. 2011. Health effects of energy drinks on children, adolescents, and young adults. Pediatrics 127:511-28.

Sidossis, L.S., Stuart, C.A., Shulman, G.I., Lopaschuk, G.D., Wolfe, R.R. 1996. Glucose plus insulin regulate fat oxidation by controlling the rate of fatty acid entry into the mitochondria. Journal of Clinical Investigation 98:2244-50.

Steen, S.N. 1996. Timely statement of The American Dietetic Association: nutrition guidance for adolescent athletes in organized sports. Journal of the American Dietetic Association 96:611-2.

Stephens, B.R., Cole, A.S., Mahon, A.D. 2006. The influence of biological maturation on fat and carbohydrate metabolism during exercise in males. International Journal of Sport Nutrition and Exercise Metabolism 16:166-79.

Sunehag, A.L., Toffolo, G., Campioni, M., Bier, D.M., Haymond, M.W. 2005. Effects of dietary macronutrient intake on insulin sensitivity and secretion and glucose and lipid metabolism in healthy, obese adolescents. Journal of Clinical Endocrinology and Metabolism 90:4496-502.

Sunehag, A.L., Toffolo, G., Treuth, M.S., Butte, N.F., Cobelli, C., Bier, D.M., Haymond, M.W. 2002. Effects of dietary macronutrient content on glucose metabolism in children. Journal of Clinical Endocrinology and Metabolism 87:5168-78.

Tamminen, K.A., Holt, N.L., Crocker, P.R. 2012. Adolescent athletes: psychosocial challenges and clinical concerns. Current Opinion in Psychiatry 25:293-300.

Tarnopolsky, M.A. 2008. Sex differences in exercise metabolism and the role of 17-beta estradiol. Medicine and Science in Sports and Exercise 40:648-54.

Tarnopolsky, M.A., Bosman, M., Macdonald, J.R., Vandeputte, D., Martin, J., Roy, B.D. 1997. Postexercise protein-carbohydrate and carbohydrate supplements increase muscle glycogen in men and women. Journal of Applied Physiology 83:1877-83. 
Tarnopolsky, M.A., Atkinson, S.A., Phillips, S.M., MacDougall, J.D. 1995. Carbohydrate loading and metabolism during exercise in men and women. Journal of Applied Physiology 78:1360-8.

Timmons, B.W., Bar-Or, O., Riddell, M.C. 2007a. Influence of age and pubertal status on substrate utilization during exercise with and without carbohydrate intake in healthy boys. Applied Physiology Nutrition and Metabolism 32:416-25.

Timmons, B.W., Bar-Or, O., Riddell, M.C. 2007b. Energy substrate utilization during prolonged exercise with and without carbohydrate intake in preadolescent and adolescent girls. Journal of Applied Physiology103:995-1000.

Timmons, B.W., Tarnopolsky, M.A., Bar-Or, O. 2004. Immune responses to strenuous exercise and carbohydrate intake in boys and men. Pediatric Research 56:227-34.

Timmons, B.W., Bar-Or, O., Riddell, M.C. 2003. Oxidation rate of exogenous carbohydrate during exercise is higher in boys than in men. Journal of Applied Physiology 94:278-84.

Tolfrey, K., Jeukendrup, A.E., Batterham, A.M. 2010. Group- and individual-level coincidence of the 'Fatmax' and lactate accumulation in adolescents. European Journal of Applied Physiology 109:1145-53.

Treuth, M.S., Sunehag, A.L., Trautwein, L.M., Bier, D.M., Haymond, M.W., Butte, N.F. 2003. Metabolic adaptation to high-fat and high-carbohydrate diets in children and adolescents. American Journal of Clinical Nutrition 77:479-89.

U.S. Department of Health and Human Services \& U.S. Department of Agriculture. 2010. Dietary Guidelines for Americans. www.dietaryguidelines.gov.

van Strien, T., Oosterveld, P. 2008. The children's DEBQ for assessment of restrained, emotional, and external eating in 7- to 12-year-old children. International Journal of Eating Disorders 41:72-81.

Walker, J.L., Heigenhauser, G.J., Hultman, E., Spriet, L.L. 2000. Dietary carbohydrate, muscle glycogen content, and endurance performance in well-trained women. Journal of Applied Physiology 88:2151-8.

Wallis, G.A., Dawson, R., Achten, J., Webber, J., Jeukendrup, A.E. 2006. Metabolic response to carbohydrate ingestion during exercise in males and females. American Journal of Physiology Endocrinology and Metabolism 290:E708-15.

Wee, S., Williams, C., Tsintzas, K., Boobis, L. 2005. Ingestion of a high glycemic index meal increases muscle glycogen storage at rest but augments its utilization during subsequent exercise. Journal of Applied Physiology 99:707-714.

Wiita, B.G., Stombaugh, I.A. 1996. Nutrition knowledge, eating practices, and health of adolescent female runners: a 3-year longitudinal study. International Journal of Sport Nutrition 6:414-25. 
Wilk, B., Timmons, B.W., Bar-Or, O. 2010. Voluntary fluid intake, hydration status, and aerobic performance of adolescent athletes in the heat. Applied Physiology Nutrition and Metabolism 35:834-41.

Wilk, B., Rivera-Brown, A.M., Bar-Or, O. 2007. Voluntary drinking and hydration in nonacclimatized girls exercising in the heat. European Journal of Applied Physiology 101:727-34.

Wilk, B., Bar-Or, O. 1996. Effect of drink flavor and NaCL on voluntary drinking and hydration in boys exercising in the heat. Journal of Applied Physiology 80:1112-7.

Williams, C., Lamb, D. 2008. Does a high-carbohydrate breakfast improve performance? Sports Science Exchange 21: 88-95.

Zakrzewski, J.K., Stevenson, E.J., Tolfrey, K. 2012. Effect of breakfast glycemic index on metabolic responses during rest and exercise in overweight and non-overweight adolescent girls. European Journal of Clinical Nutrition 66:436-42.

\section{Table 2 references:}

Iglesias-Gutiérrez, E., García-Rovés, P.M., Rodríguez, C., Braga, S., García-Zapico, P., Patterson, A.M. 2005. Food habits and nutritional status assessment of adolescent association football players. A necessary and accurate approach. Canadian Journal of Applied Physiology 30:18-32.

Cupisti, A., D'Alessandro, C., Castrogiovanni, S., Barale, A., Morelli, E. 2002. Nutrition knowledge and dietary composition in Italian adolescent female athletes and non-athletes. International Journal of Sport Nutrition and Exercise Metabolism 12:207-19.

Giovannini, M., Agostoni, C., Giannı', M., Bernardo, L., Riva, E. 2000. Adolescence: Macronutrient needs. European Journal of Clinical Nutrition 54:S7-S10.

Bar-Or, O., Unnithan, V. B. 1994. Nutritional requirements of young association football players. Journal of Sports Science 12:S39-S42.

Boisseau, N., Le Creff, C., Loyens, M., \& Poortmans, J. R. 2002. Protein intake and nitrogen balance in male non-active adolescent and association football players. European Journal of Applied Physiology 88:288-93.

Rico-Sanz, J., Frontera, W., Mole, P.A., Rivera, M.A., Rivera-Brown, A., Meredith, C. 1998. Dietary and performance assessment of elite association football players during a period of intense training. International Journal of Sport Nutrition 8:230-40.

Hickson, J.F., Duke, M.A., Risser, W.L., Palmer, R., Stockton, J.E. 1987. Nutritional intake from food sources of high school football athletes. Journal of the American Dietetic Association 87:1656-9.

Papadopoulou, S.K., Papadopoulou, S.D., Gallos, G.K. 2002. Macro- and micro-nutrient intake of adolescent Greek female volleyball players. International Journal of Sport Nutrition and Exercise Metabolism 12:73-80. 
Horswill, C., Park, S., Roemmich, J. 1990. Changes in the protein nutritional status of adolescent wrestlers. Medicine and Science in Sports and Exercise 22:599-604.

Benardot, D., Schwarz, M., Heller, D.W. 1989. Nutrient intake in young, highly competitive gymnasts. Journal of the American Dietetic Association 3:401-03.

Malczewska, J., Raczynski, G., Stupnicki, R. 2000. Iron status in female endurance athletes and in non-athletes. International Journal of Sport Nutrition and Exercise Metabolism $10: 260-76$

Ousley-Pahnke, L., Black, D.R., Gretebeck, R.J.2001. Dietary intake and energy expenditure of female collegiate swimmers during decreased training prior to competition. Journal of the American Dietetic Association 101:351-4.

Ziegler, P.J., Jonnalagadda, S.S., Nelson, J.A., Lawrence, C., Baciak, B. 2002. Contribution of meals and snacks to nutrient intake of male and female elite figure skaters during peak competitive season. Journal of the American College of Nutrition 21:114-9. 
Table 1. Estimated daily total energy (kcal) needs by age, sex, and physical activity level

\begin{tabular}{|c|c|c|c|c|}
\hline \multirow{2}{*}{ Sex } & \multirow{2}{*}{ Age (years) } & \multicolumn{3}{|c|}{ Physical activity level } \\
\hline & & Sedentary & Moderately active & Active \\
\hline \multirow{3}{*}{ Female } & 4 to 8 & 1200 to 1400 & 1400 to 1600 & 1400 to 1800 \\
\hline & 9 to 13 & 1400 to 1600 & 1600 to 2000 & 1800 to 2200 \\
\hline & 14 to 18 & 1800 & 2000 & 2400 \\
\hline \multirow{3}{*}{ Male } & 4 to 8 & 1200 to 1400 & 1400 to 1600 & 1600 to 2000 \\
\hline & 9 to 13 & 1600 to 2000 & 1800 to 2200 & 2000 to 2600 \\
\hline & 14 to 18 & 2000 to 2400 & 2400 to 2800 & 2800 to 3200 \\
\hline
\end{tabular}

Source: Dietary Guidelines for Americans (2010). The values in Table 1 may be used in conjunction with the AMDR for $\mathrm{CHO}$ (45 to 65\% of total energy intake) to estimate CHO needs specific to age, sex and physical activity level. 
Table 2. Examples of reported CHO intakes in young athletes

\begin{tabular}{|c|c|c|c|c|}
\hline Author (date) & Sport/event & Age (y) & Sex & CHO intake $\left(\mathrm{g} \cdot \mathrm{d}^{-1}\right)$ \\
\hline $\begin{array}{l}\text { Malczewska et al. } \\
(2000)\end{array}$ & $\begin{array}{l}\text { Mixed endurance } \\
\qquad(\mathrm{n}=93)\end{array}$ & $17(1)$ & $\mathrm{F}$ & 352 (127) \\
\hline $\begin{array}{l}\text { Benardot et al. } \\
\text { (1989) }\end{array}$ & $\begin{array}{l}\text { Gymnastics } \\
(n=29)\end{array}$ & $7-10$ & $\mathrm{~F}$ & $219(57)$ \\
\hline $\begin{array}{l}\text { Benardot et al. } \\
\text { (1989) }\end{array}$ & $\begin{array}{l}\text { Gymnastics } \\
(\mathrm{n}=22)\end{array}$ & $11-14$ & $\mathrm{~F}$ & 227 (64) \\
\hline $\begin{array}{l}\text { Ziegler et al. } \\
\text { (2002) }\end{array}$ & $\begin{array}{l}\text { Figure skating } \\
\qquad(\mathrm{n}=48)\end{array}$ & $15(2)$ & $\mathrm{F}$ & $243(111)$ \\
\hline $\begin{array}{l}\text { Horswill et al. } \\
\text { (1990) }\end{array}$ & $\begin{array}{l}\text { Wrestling } \\
(\mathrm{n}=18)\end{array}$ & $16(2)$ & M & $\begin{array}{l}367 \text { (123) (BWL) } \\
209 \text { (136) (DWL) }\end{array}$ \\
\hline $\begin{array}{l}\text { Hickson et al. } \\
\text { (1987) }\end{array}$ & $\begin{array}{l}\text { US football } \\
\quad(n=46)\end{array}$ & $12-14$ & M & 302 (125) \\
\hline $\begin{array}{l}\text { Hickson et al. } \\
\text { (1987) }\end{array}$ & $\begin{array}{l}\text { US football } \\
\qquad(\mathrm{n}=88)\end{array}$ & $15-18$ & M & $366(170)$ \\
\hline $\begin{array}{l}\text { Papadopoulou et al. } \\
\text { (2002) }\end{array}$ & $\begin{array}{l}\text { Volleyball } \\
\text { (n=65) }\end{array}$ & $14-19$ & $\mathrm{~F}$ & 195 (88) \\
\hline $\begin{array}{l}\text { Rico-Sanz et al. } \\
\text { (1998) }\end{array}$ & $\begin{array}{l}\text { Association football } \\
\qquad(\mathrm{n}=8)\end{array}$ & $17(2)$ & M & $526(62)$ \\
\hline
\end{tabular}

Mean (SD); BWL = pre-season before weight loss; DWL = during-season during weight loss 
Table 3. Studies investigating the effect of $\mathrm{CHO}$ intake during exercise on metabolism and performance

\begin{tabular}{|c|c|c|c|c|c|}
\hline Author(s) & Participants & Experimental design & $\begin{array}{l}\text { Contribution } \\
\text { of } \mathrm{CHO}_{\text {exo }} \\
\text { oxidation to } \\
\text { total EE } \\
\end{array}$ & Metabolic effect of CHO ingestion & $\begin{array}{c}\text { Performance } \\
\text { effect }\end{array}$ \\
\hline $\begin{array}{l}\text { Hendelman } \\
\text { et al. } \\
\text { (1997) }\end{array}$ & $\begin{array}{c}13 \delta^{\pi} \\
14.9(0.5) \mathrm{y}\end{array}$ & $\begin{array}{l}\text { Candy bar ( } 280 \mathrm{kcal}, 36 \mathrm{~g} \mathrm{CHO}) \text {, fat- } \\
\text { free fig bars ( } 200 \mathrm{kcal}, 44 \mathrm{~g} \mathrm{CHO}) \text { or } \\
\text { placebo consumed } 10 \text { min before } 75 \\
\text { min CE @ } 60 \% \mathrm{VO}_{2 \text { peak }} \\
+2500 \mathrm{~m} \text { CE time trial }\end{array}$ & Not assessed & No effect between conditions & $\begin{array}{l}\text { No effect between } \\
\text { conditions }\end{array}$ \\
\hline $\begin{array}{l}\text { Riddell et } \\
\text { al. } \\
\text { (2000a) }\end{array}$ & $\begin{array}{c}8 \overbrace{}^{\lambda} \\
13 \text { to } 17 y\end{array}$ & $\begin{array}{l}\text { Placebo or glucose drink (3 g } \\
\left.\text { glucose } \cdot \mathrm{kg} \mathrm{BM}^{-1}\right) \\
\text { consumed during } \\
120 \text { min CE @ } 60 \% \mathrm{VO}_{2 \text { peak }}\end{array}$ & $\sim 25 \%$ & $\begin{array}{c}\uparrow \mathrm{CHO} \text { oxidation } \\
\downarrow \text { fat oxidation } \\
\uparrow \text { blood glucose and plasma insulin } \\
\downarrow \mathrm{CHO}_{\text {endo }}\end{array}$ & $\downarrow$ RPE \\
\hline $\begin{array}{l}\text { Riddell et } \\
\text { al. } \\
\text { (2001) }\end{array}$ & $\begin{array}{c}12 \overbrace{}^{\lambda} \\
10 \text { to } 14 \mathrm{y}\end{array}$ & $\begin{array}{l}\text { Placebo, 6\% glucose (G), or 3\% } \\
\text { fructose plus 3\% glucose (FG) } \\
\text { consumed during } 90 \text { min CE @ 53\% } \\
+\mathrm{VO}_{2 \text { peak }} \mathrm{TT}_{\mathrm{ex}} \text { test @ 90\% PP }\end{array}$ & $\begin{array}{c}17 \% \text { in } G \\
16 \% \text { in } F G\end{array}$ & $\begin{array}{c}\uparrow \mathrm{CHO} \text { oxidation in } \mathrm{G} \text { and } \mathrm{FG} \\
\downarrow \text { fat oxidation in G and FG } \\
\uparrow \text { lactate in G and FG } \\
\uparrow \text { insulin and glucose in G }\end{array}$ & $\begin{array}{c}\mathrm{G} \downarrow \mathrm{TT}_{\mathrm{ex}} 25 \% \\
\mathrm{FG} \downarrow \mathrm{TT}_{\mathrm{ex}} 40 \%\end{array}$ \\
\hline $\begin{array}{l}\text { Timmons et } \\
\text { al. } \\
\text { (2003) }\end{array}$ & $\begin{array}{c}12 \text { ð } \\
9.8 \mathrm{y} \\
(\mathrm{PP} \text { and } \mathrm{EP}) \\
10 \text { men } \\
22.1 \mathrm{y}\end{array}$ & $\begin{array}{c}\text { Placebo or 6\% CHO drink (4\% } \\
\text { sucrose, 2\% glucose) } \\
\text { consumed during } \\
60 \text { min CE @ 70\% VO } \mathrm{VO}_{2 \text { peak }}\end{array}$ & $\begin{array}{l}22 \% \text { boys } \\
15 \% \text { men }\end{array}$ & $\begin{array}{c}\uparrow \text { CHO oxidation } \\
\downarrow \text { fat oxidation } \\
\uparrow \text { post-ex blood glucose \& lactate } \\
\downarrow \mathrm{CHO}_{\text {endo }}(24 \% \text { boys; } 15 \% \text { men }) \\
\text { Age-related effects: } \\
\uparrow \text { fat } \& \downarrow \mathrm{CHO} \text { oxidation in } \\
\text { boys vs. men. } \\
\downarrow \mathrm{CHO}_{\text {endo }} \text { and } \uparrow \mathrm{CHO} \text { exo oxidation in } \\
\text { boys vs. men (CHO trial) }\end{array}$ & Not assessed \\
\hline
\end{tabular}




\begin{tabular}{|c|c|c|c|c|c|}
\hline $\begin{array}{l}\text { Timmons et } \\
\text { al. } \\
(2007 a)\end{array}$ & $\begin{array}{c}20 \lesssim \\
12 \mathrm{y} \\
(7 \mathrm{PP}, 7 \mathrm{EP}, \\
6 \mathrm{M}-\mathrm{LP}) \\
9 \widehat{0} \\
14 \mathrm{y}\end{array}$ & $\begin{array}{c}\text { Placebo or 6\% CHO drink (4\% } \\
\text { sucrose, } 2 \% \text { glucose) } \\
\text { consumed during } \\
60 \text { min CE @ } 70 \% \mathrm{VO}_{2 \text { peak }}\end{array}$ & $\begin{array}{l}\text { 30\% in } \\
\text { PP and EP } \\
\text { 24\% in M-LP } \\
\text { and } 14 \text { y boys }\end{array}$ & $\begin{array}{c}\uparrow \mathrm{CHO} \text { oxidation } \\
\downarrow \text { fat oxidation } \\
\uparrow \text { post-exercise blood glucose and } \\
\text { lactate } \\
\downarrow \mathrm{CHO}_{\text {endo oxidation }} \\
\text { Age and puberty-related effects: } \\
\uparrow \text { fat oxidation in younger vs. older } \\
\text { boys } \\
\downarrow \mathrm{CHO}_{\text {endo }} \text { in younger vs. older boys } \\
\uparrow \mathrm{CHO}_{\text {exo }} \text { Oxidation (\% total EE) in } \\
\text { younger vs. older boys and M-LP vs. } \\
\text { PP and EP }\end{array}$ & Not assessed \\
\hline $\begin{array}{c}\text { Timmons et } \\
\text { al } \\
(2007 \mathrm{~b})\end{array}$ & $\begin{array}{c}12 \stackrel{+}{+} \\
12 \mathrm{y}(\mathrm{YG}) \\
10 \stackrel{\circ}{\circ} \\
14 \mathrm{y}(\mathrm{OG})\end{array}$ & $\begin{array}{c}\text { Placebo or 6\% CHO drink (4\% } \\
\text { sucrose, } 2 \% \text { glucose) } \\
\text { consumed during } \\
60 \text { min CE @ } 70 \% \mathrm{VO}_{2 \text { peak }}\end{array}$ & $\begin{array}{c}\sim 19 \% \\
\text { (similar in } \\
\text { YG and OG) }\end{array}$ & $\begin{array}{c}\downarrow \text { fat oxidation in YG (not OG) } \\
\downarrow \mathrm{CHO}_{\text {endo }} \text { oxidation in OG (not YG) } \\
\text { Age-related effects: } \\
\downarrow \mathrm{CHO}_{\text {endo oxidation in YG vs. OG. }} \\
\uparrow \text { fat oxidation in YG during placebo }\end{array}$ & Not assessed \\
\hline $\begin{array}{l}\text { Riddell et } \\
\text { al. } \\
\text { (2000b) }\end{array}$ & $\begin{array}{c}8 \text { ๙ } \\
\text { 15.7(0.7) y } \\
\text { with IDDM } \\
6 \text { ठ } \\
\text { 14.9(0.6) y } \\
\text { non-diabetic }\end{array}$ & $\begin{array}{l}\text { Placebo or } 8 \% \text { glucose drink } \\
\text { consumed during } \\
60 \text { min CE @ 59\% VO } \text { 2peak }^{2}\end{array}$ & $\begin{array}{l}9 \% \text { IDDM } \\
12 \% \text { non- } \\
\text { diabetic }\end{array}$ & $\begin{array}{c}\text { Similar CHO oxidation } \\
\downarrow \text { fat oxidation (tendency) } \\
\downarrow \mathrm{CHO}_{\text {endo }} \\
\text { Between-group differences: } \\
\uparrow \text { blood glucose and plasma insulin } \\
\text { concentrations in IDDM vs. controls } \\
\downarrow \mathrm{CHO}_{\text {exo }} \text { in IDDM vs. controls }\end{array}$ & Not assessed \\
\hline $\begin{array}{l}\text { Chu et al. } \\
\text { (2011) }\end{array}$ & $\begin{array}{c}7 \hat{0} \\
11(1) \mathrm{y} \\
\text { obese }\end{array}$ & $\begin{array}{l}\text { Placebo or } 6 \% \text { glucose drink } \\
\text { consumed during } \\
60 \text { min CE @ Fatmax }\end{array}$ & $23 \%$ & $\begin{array}{l}\uparrow \text { CHO oxidation } \\
\downarrow \text { fat oxidation }\end{array}$ & Not assessed \\
\hline
\end{tabular}

$\mathrm{EE}$ - energy expenditure; $\mathrm{CHO}_{\mathrm{exo}}$ - exogenous carbohydrate oxidation; $\mathrm{CHO}_{\text {endo }}$ - endogenous carbohydrate oxidation; $\mathrm{CE}$ - cycle ergometry; $\mathrm{TT}_{\mathrm{ex}}$ - time trial to exhaustion; PP - peak power; $\widehat{o}$ - boys, $q$ - girls; PP - prepubertal, EP- early pubertal, M-LP - mid to late pubertal 